\title{
An anatomical study about the arthroscopic repair of the lateral ligament of the ankle
}

\author{
João Torrinha Jorge ${ }^{\mathrm{a}, *}$, Tiago Mota Gomes ${ }^{\mathrm{b}}$, Xavier Martin Oliva ${ }^{\mathrm{c}, \mathrm{d}}$ \\ a Department of Orthopedic Surgery, Hospital Curry Cabral - CHLC, Rua da Beneficência no. 8, 1069-166 Lisboa, Portugal \\ b University of Barcelona, Calle Casanova, 143, 08038 Barcelona, Spain \\ ${ }^{\mathrm{c}}$ Department of Human Anatomy, Dissection Room, Faculty of Medicine, University of Barcelona, Calle Casanova, 143, 08038 Barcelona, Spain \\ ${ }^{\mathrm{d}}$ Foot and Ankle Surgery, Remei Hospital, Barcelona, Spain
}

\section{A R T I C L E I N F O}

\section{Article history:}

Received 11 November 2016

Received in revised form 14 December 2016

Accepted 11 January 2017

\section{Keywords:}

Anatomy

Anterior talofibular ligament

Superficial peroneal nerve

Inferior extensor retinaculum

Minimally invasive surgery

Ankle instability

\begin{abstract}
A B S T R A C T
Background: The purpose of this anatomical study to was to determine the relationship of the structures involved in the arthroscopic repair of the anterior talofibular ligament.

Methods: Dissection of fifteen lower leg cadaveric specimens was made and distances in the anterior direction from the reference-point at the lateral malleolus origin of the anterior talofibular ligament were measured, to the talar insertion of the ligament, to the superficial peroneal nerve at $60^{\circ}$ and $90^{\circ}$ in relation to the lateral malleolus axis in the sagittal plane, and to the inferior extensor retinaculum. Results: The mean \pm SD distance to superficial peroneal nerve from the reference-point was $25 \pm 6$ (range 17-35) $\mathrm{mm}$ at $60^{\circ}$, and $32 \pm 9$ (range 24-48) $\mathrm{mm}$ at $90^{\circ}$ in relation to the lateral malleolus axis. The mean \pm SD distance to the inferior extensor retinaculum was $20 \pm 5$ (range 14-29) $\mathrm{mm}$. The mean $\pm \mathrm{SD}$ length of the anterior talofibular ligament was $21 \pm 4$ (range 13-29) $\mathrm{mm}$.

Conclusions: The superficial peroneal nerve demonstrated the greatest variance in its anatomy. An accessory incision to include the inferior extensor retinaculum in the repair should not surpass the $22 \mathrm{~mm}$ distance from the lateral malleolus in the anterior direction, due to the risk of damaging the nerve. (c) 2017 European Foot and Ankle Society. Published by Elsevier Ltd. All rights reserved.
\end{abstract}

\section{Introduction}

Ankle sprains are one of the most common sports related injury. Around $80 \%$ of the sprains are related to the anterior talofibular ligament (ATFL), while the remaining 20\% affect both the ATFL and calcaneofibular ligament (CFL). Rarely, the posterior talofibular ligament is involved [1].

Most ankle sprains recover fully with non-operative treatment but 20-30\% develop chronic ankle instability [2]. Mechanical instability is due to the laxity caused by ligaments tears and poor healing, whereas functional instability is due to proprioceptive and muscular deficits after ankle sprain. Nevertheless they often occur as a combination [3].

The classic Brostrom procedure is a repair of the lateral ligaments including the ATFL and the CFL, frequently associated with a proximal advancement of the inferior extensor retinaculum (IER), the Gould modification. This remains the first-line procedure

Abbreviations: ATFL, anterior talofibular ligament; CFL, calcaneofibular ligament; IER, inferior extensor retinaculum; SD, standard deviation.

* Corresponding author.

E-mail address: joao.torrinha.jorge@gmail.com (J.T. Jorge). for patients with chronic lateral ankle ligament laxity requiring surgical treatment.

The long-term results of the non-anatomic reconstructions of the lateral ankle ligaments revealed an increased incidence of degenerative changes in the hind foot, and its use have decayed in favor of other procedures [2].

Anatomic reconstruction with tendon graft or transfer procedures require precise placement and tensioning of the graft. Failure to achieve this may alter the biomechanics of the joints resulting in joint loading alterations. Generally these types of procedures have been reserved for patients who have failed a prior Brostrom-Gould repair or patients who may stress their ankle to a greater degree than normal (high body mass index, heavy labor occupation, sports requirements, or congenital ligament laxity) [2].

Studies have reported a high incidence of intra-articular pathology associated with chronic ankle instability and some recommend an ankle arthroscopy simultaneously when a surgical repair is chosen [4-6].

Moreover, several arthroscopically assisted or minimally invasive surgery procedures to achieve lateral ankle stabilization have been described in the orthopedic literature in recent years.

The first arthroscopic repair technique was reported in 1987, and consisted in the use of staples as a fixation method [7]. In 
another technique described a bone tunnel was used but without a clinical analysis [8].

The majority of the minimally invasive procedures performed nowadays require a suture anchor fixation. In general, they have in common the exposure of the anatomic origin of the lateral ligaments on the distal fibula followed by placement of one or more suture anchors into the fibula. They differ in the passage of the sutures through the ATFL, CFL, and retinaculum to affect a repair/augmentation procedure. Although there has been an increasing number of techniques described, only eleven papers with clinical results have been published in English literature [9-19], presented in Table 1.

These studies appear to show good results with short-term follow-up, in spite of having a high rate of complications in some series, ranging from 0 to $36 \%$. Iatrogenic damage to the superficial peroneal nerve (SPN) is frequently reported.

The techniques used standard anterolateral and anteromedial portals for the anterior ankle arthroscopy and placement of the anchors. Most authors also described an accessory incision ranging $10-20 \mathrm{~mm}$ anterior to the tip of the lateral malleolus to pass the sutures trough the ATFL and the IER.

The anterior talofibular ligament is closely related to the ankle joint capsule and is typically composed of one, two or three separate bands. It originates at the anterior margin of the lateral malleolus, and its center is on average $10 \mathrm{~mm}$ proximal to the tip of the fibula as measured along the axis of the fibula, with an overall width of $6-10 \mathrm{~mm}$. Runs in a anteromedial direction into its insertion on the talar body immediately anterior to the joint surface, being virtually horizontal to the ankle in the neutral position [20]. The fibular obscure tubercle was described previously as a tubercle anterior to the apex of the fibula, and its utility as a landmark is not clear [21]. The inferior extensor retinaculum is a thickened portion of the sural fascia, with a X or Y shape. An attachment of the IER to the fibular periosteum can function in a role similar to that of the calcaneofibular ligament (CFL) in stabilizing the subtalar joint, although this theory has been questioned [22].

Proper anatomic knowledge is important for a correct surgical treatment. There are several studies already published that make a description of the branch variation of the superficial peroneal nerve or its relation to the anterior ankle arthroscopic portals $[23,24]$.

Nonetheless we believe that a more directed study for the repair of the ATFL through mini-invasive procedures can be useful, than just for the anterior arthroscopy of the ankle in general. Additionally, more accurate information is obtained from the calculation of the distances to an palpable and identifiable landmark.

Table 1

Studies of anterior talofibular ligament arthroscopic repair with suture anchors.

\begin{tabular}{|c|c|c|c|c|c|c|}
\hline \multirow[t]{2}{*}{ Study (year) } & \multirow{2}{*}{$\begin{array}{l}\text { No. of } \\
\text { ankles }\end{array}$} & \multirow{2}{*}{$\begin{array}{l}\text { Mean age } \\
\text { in years (range) }\end{array}$} & \multirow{2}{*}{$\begin{array}{l}\text { Mean follow-up in } \\
\text { months (range) }\end{array}$} & \multicolumn{2}{|c|}{ AOFAS score ${ }^{a}$} & \multirow{2}{*}{$\begin{array}{l}\text { Complications } \\
\text { (no. of ankles) }\end{array}$} \\
\hline & & & & Pre-op & Post-op & \\
\hline $\begin{array}{l}\text { Corte-Real and } \\
\text { Moreira [9] }\end{array}$ & 28 & $33(15-54)$ & $28(6-48)$ & NA & $85(65-100)$ & $\begin{array}{l}\text { Delayed wound healing ( } 3 \text { ) } \\
\text { Superficial peroneal nerve numbness ( } 3 \text { [1 persistent]) } \\
\text { Additional acute ankle sprain ( } 2 \text { ) } \\
\text { Deep venous thrombosis ( } 1 \text { ) } \\
\text { Total } 32 \%(9)\end{array}$ \\
\hline Nery et al. [10] & 38 & $29(15-53)$ & $118(72-168)$ & NA & $90(44-100)$ & $\begin{array}{l}\text { No complications ( } 2 \text { ankles with low AOFAS score }{ }^{\mathrm{a}}, 44 \text { and } \\
\text { 47). }\end{array}$ \\
\hline Kim et al. [11] & 28 & $39(22-55)$ & $16(13-25)$ & $61 \pm 16$ & $92 \pm 6$ & $\begin{array}{l}\text { Portal-site irritation (4) } \\
\text { Superficial infection (1) } \\
\text { Prominent asymptomatic suture knots (3) } \\
\text { Additional acute ankle sprain (2) } \\
\text { Total } 36 \%(10)\end{array}$ \\
\hline Vega et al. [12] & 16 & $29(17-46)$ & $29(17-46)$ & $67(59-77)$ & $97(95-100)$ & $\begin{array}{l}\text { Delayed wound healing (1) } \\
\text { Superficial infection (1) } \\
\text { Total } 13 \%(2)\end{array}$ \\
\hline $\begin{array}{l}\text { Cottom and Rigby } \\
\text { [13] }\end{array}$ & 40 & $46(15-83)$ & $12(6-21)$ & $41(23-64)$ & $95(84-100)$ & $\begin{array}{l}\text { Deep venous thrombosis (1) } \\
\text { Neuritis of intermediate dorsal cutaneous nerve (1) } \\
\text { Distal fibular fracture (1) } \\
\text { Total } 8 \% \text { (3) }\end{array}$ \\
\hline $\begin{array}{l}\text { Labib and Slone } \\
\text { [14] }\end{array}$ & 14 & NA & $3(2-14)$ & NA & $93(80-100)$ & No complications \\
\hline $\begin{array}{l}\text { Acevedo and } \\
\text { Mangone [15] }\end{array}$ & 73 & 35 & 28 & NA & NA & $\begin{array}{l}\text { Recurrent instability (1) } \\
\text { Persistent pain ( } 3 \text { ) } \\
\text { Neuritis (5) } \\
\text { Total } 12 \%(9)\end{array}$ \\
\hline Matsui et al. [16] & 19 & 28 & 12 & NA & NA & $\begin{array}{l}\text { Numbness of the superficial peroneal nerve (2) } \\
\text { Total } 11 \%(2)\end{array}$ \\
\hline \multirow[t]{2}{*}{ Yoo and Yang [17] } & 63 & NA & 6 & $67 \pm 15$ & $97 \pm 5$ & $\begin{array}{l}\text { Inversion deficit of } 10^{\circ}(3) \text { Neuritis of the } \\
\text { intermediate dorsal cutaneous nerve }(2) \\
\text { Total } 8 \%(5)\end{array}$ \\
\hline & $\begin{array}{l}\text { (W/internal } \\
\text { brace) } 22\end{array}$ & & & $66 \pm 22$ & $98 \pm 17$ & $\begin{array}{l}\text { Inversion deficit of } 10^{\circ}(2) \\
\text { Total } 9 \%(2)\end{array}$ \\
\hline Yeo et al. [18] & 25 & 35 & 12 & $68 \pm 2$ & $90 \pm 2$ & $\begin{array}{l}\text { Superficial peroneal nerve injuries (2) } \\
\text { Sural nerve injury (1) } \\
\text { knot pain (2) } \\
\text { Total } 20 \%(5)\end{array}$ \\
\hline Cottom et al. [19] & 45 & $45(16-75)$ & $14(12-20)$ & $49 \pm 3$ & $95 \pm 4$ & $\begin{array}{l}\text { Superficial infection (3) } \\
\text { Total } 7 \%(3)\end{array}$ \\
\hline
\end{tabular}

a American Orthopedic Foot and Ankle Society score. 
With this in mind, the purpose of this anatomical study was to determine the relationship of relevant structures in the lateral region of the ankle to the origin of the ATFL in the lateral malleolus. In particular the distances to the SPN and the IER, therefore providing a better approach to minimally invasive procedures to ATFL repair.

\section{Materials and methods}

Fifteen lower legs amputated from below the knee were obtained from fresh frozen cadavers of white origin (eight right and seven left). The age and conditions of the specimens were not known. After screening, no deformities, pre-existing scars and other pathologies that could alter the anatomy were found.

All the cadaveric studies were performed at University of Barcelona in Catalonia, Spain, with all specimens being obtained from the body donation program of this University.

The specimens were laid on their medial surface, maintaining the ankle in neutral position. An exposure of the lateral structures of the ankle was made, with a careful dissection of the cutaneous and subcutaneous fat tissue. The superficial peroneal nerve and IER were identified and avoided. Then a window was created in the sural fascia, posterior to the IER, to allow visualization of the ATFL and CFL (Figs. 1 and 2).

The number of ATFL bands (single, double or triple) was noted. As described in previous studies, we considered a band as a collection of fascicles separated by a interval that would allow the passage of vascular branches [20,25].

The measurements were made with the reference-point at the peroneal origin of the ATFL, in the middle of its width $(10 \mathrm{~mm}$ from the tip of the lateral malleolus), or the center of the most superior bundle when the ATFL had multiple bundles.

The following distances were measured:

- The distance from the ATFL origin center to the superficial peroneal nerve was measured at $60^{\circ}$ and at $90^{\circ}$ in relation to the

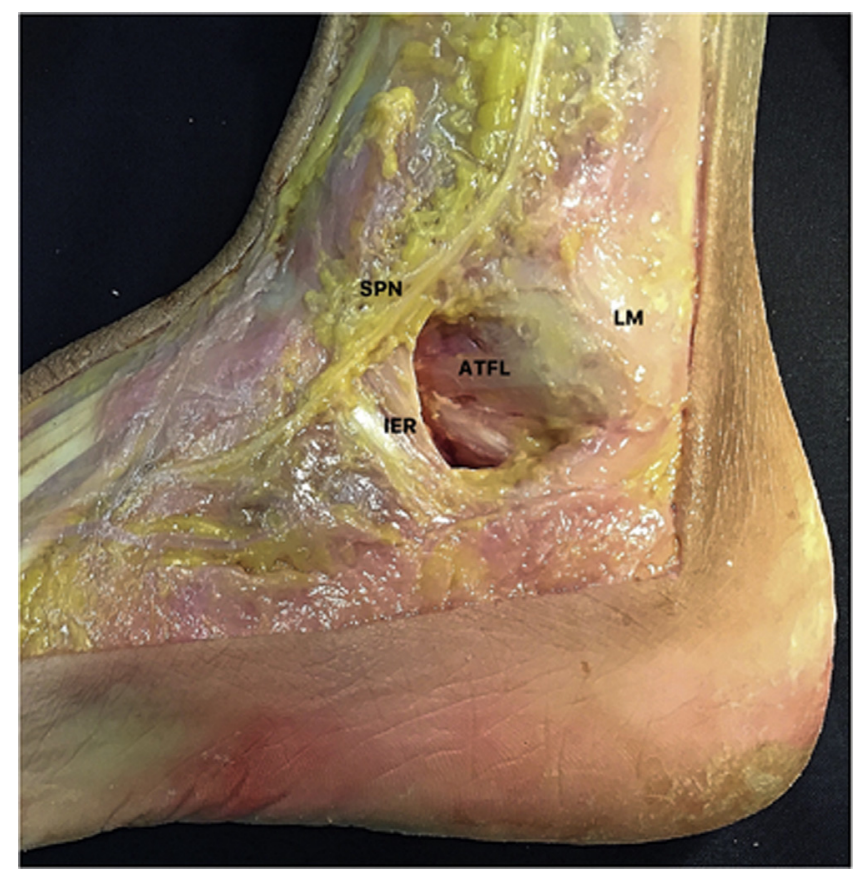

Fig. 1. Lateral view of the the position of a left ankle in neutral, with a superficial dissection of the lateral structures. ATFL - anterior talofibular ligament; SPN superficial peroneal nerve; IER - inferior extensor retinaculum; LM - lateral malleolus.

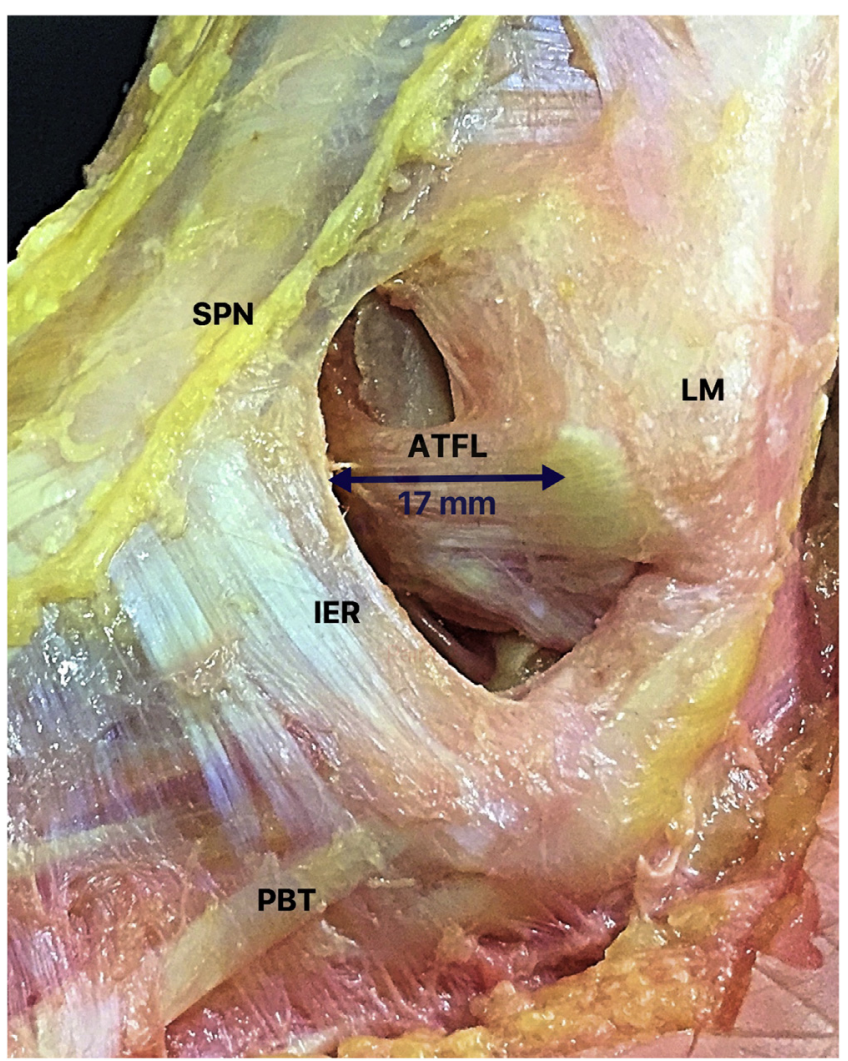

Fig. 2. Lateral view of a left ankle, with a superficial dissection of the lateral structures. ATFL - anterior talofibular ligament; SPN - superficial peroneal nerve; IER - inferior extensor retinaculum; LM - lateral malleolus; PBT - peroneus brevis tendon. The arrow shows the distance from the ATFL origin center to the IER.

axis of the lateral malleolus in the sagittal plane. The $60^{\circ}$ angle was chosen to measure the distance in a direction adjacent to the anterolateral portal. The measurement in the $90^{\circ}$ angle was in the direction of the accessory incision, anterior to the lateral malleolus, made to pass the sutures in the arthroscopic repair techniques.

- The distance from the ATFL origin center to the IER at $90^{\circ}$ in relation to the axis of the lateral malleolus in the sagittal plane.

- The length of the ATFL from its lateral malleolus origin center at the talar insertion center was measured.

The points of measurement were marked with a needle and a ruler was used (Figs. 3 and 4). The dissections and measurements were accomplished by two independent researchers (Authors 1 and 2).

\section{Results}

The superficial peroneal nerve demonstrated the greatest variance in its anatomy, as the position of its course was very variable, especial at $90^{\circ}$ in relation to the axis of the lateral malleolus. The mean \pm SD distance from the ATFL origin center was of $25 \pm 6$ (range $17-35) \mathrm{mm}$ at $60^{\circ}$, and $32 \pm 9$ (range $\left.24-48\right) \mathrm{mm}$ at $90^{\circ}$ (Table 2 ).

The distance from the ATFL origin center to the IER was less variable than the SPN at $90^{\circ}$ in relation to the axis of the lateral malleolus, with a mean \pm SD of $20 \pm 5$ (range 14-29) mm.

In relation to the morphology of the ATFL, nine of the fifteen (60\%) specimens had single-band pattern, and six (40\%) specimens had double-band pattern. There were no triple-band pattern specimens (Figs. 5 and 6). We noted that the intersection of the 


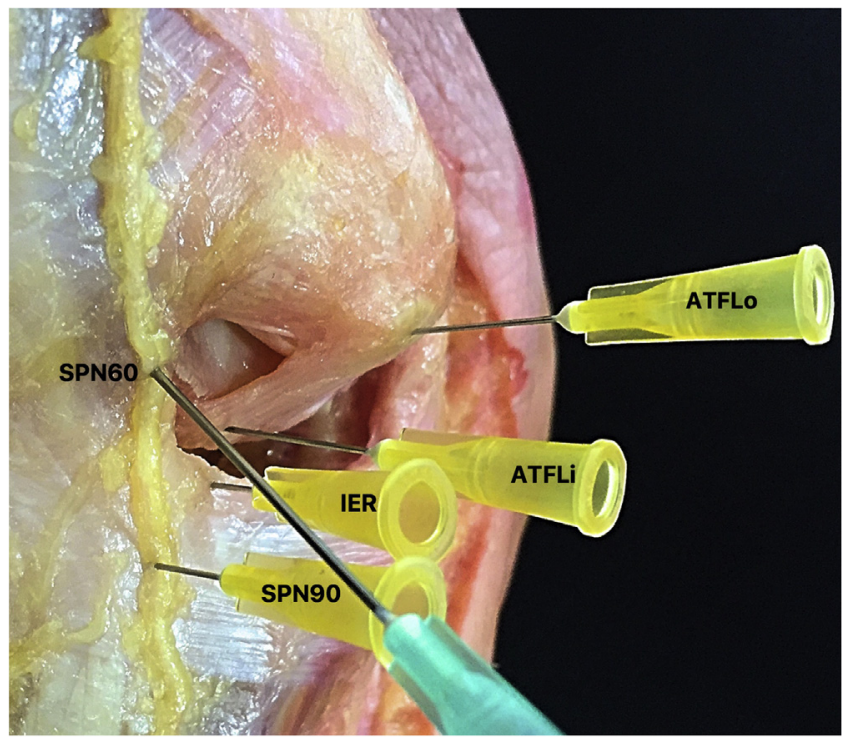

Fig. 3. Proximal view of a left ankle, with the placement of the needles to perform the measurements. ATFLo - anterior talofibular ligament origin; ATFLi - anterior talofibular ligament insertion; IER - inferior extensor retinaculum; SPN90 superficial peroneal nerve at $90^{\circ}$; SPN60 - superficial peroneal nerve at $60^{\circ}$.

ATFL and CFL was near the fibular obscure tubercle, but with some variation on its direction, and apparently more associated to the ATFL origin. Furthermore, we found in four cases (27\%) an expansion of ligament tissue between the ATFL and CFL (Fig. 8).

The measurement of the ATFL from its lateral malleolus origin center at the talar insertion center was the more consistent, with a mean \pm SD length of $21 \pm 4$ (range 13-29) $\mathrm{mm}$.

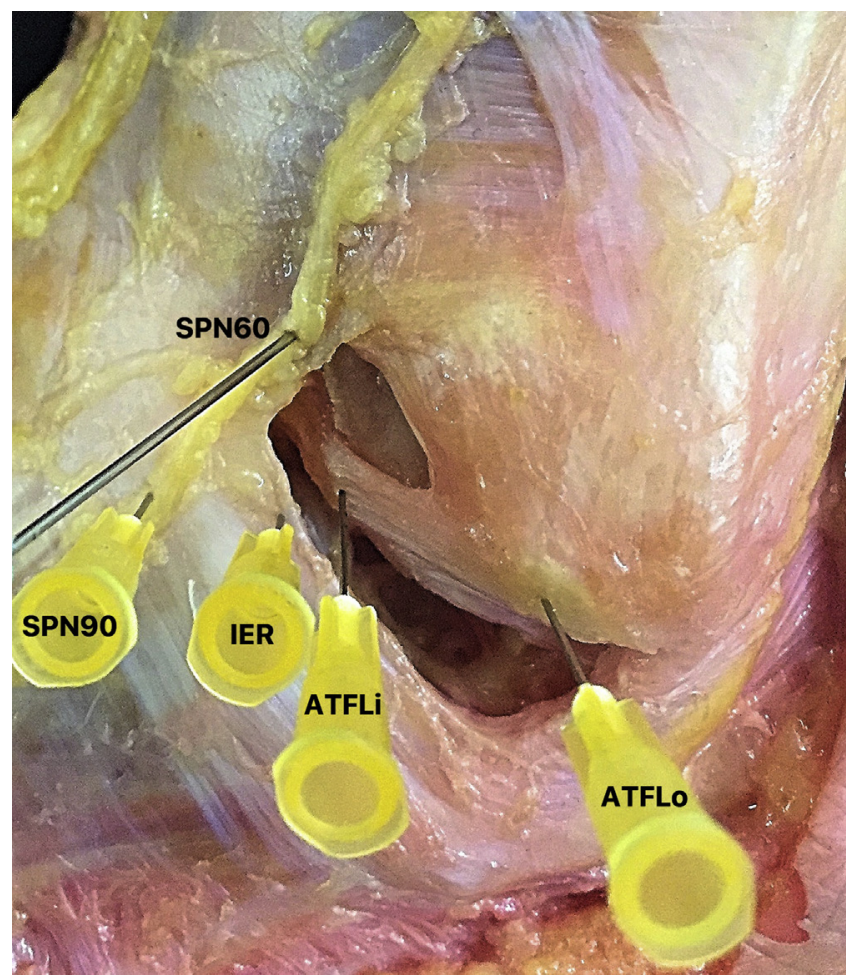

Fig. 4. Lateral view of a left ankle, with the placement of the needles to perform the measurements. ATFLo - anterior talofibular ligament origin; ATFLi - anterior talofibular ligament insertion; IER - inferior extensor retinaculum; SPN90 superficial peroneal nerve at $90^{\circ}$; SPN60 - superficial peroneal nerve at $60^{\circ}$.

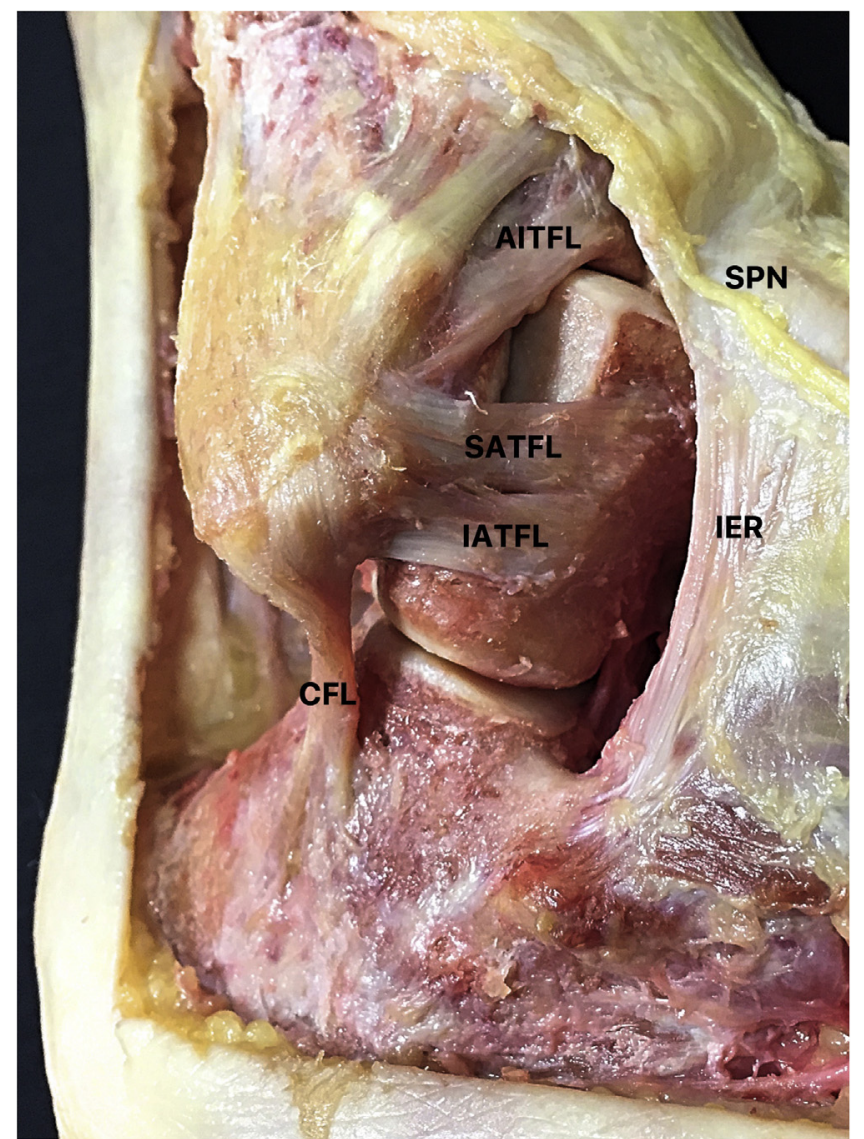

Fig. 5. Anterolateral view of an extensive dissection of the lateral ligaments in a right ankle. SATFL - superior band of the anterior talofibular ligament; IATFL inferior band of the anterior talofibular ligament; CFL - calcaneofibular ligament; AITFL - antero-inferior tibiofibular ligament; SPN - superficial peroneal nerve; IER - inferior extensor retinaculum.

\section{Discussion}

The lesion of the superficial peroneal nerve is an important cause for complications in arthroscopic ATFL repair. At $60^{\circ}$ in relation to the axis of the lateral malleolus, in a location near the anterolateral portal, the mean distance from the ATFL origin center

Table 2

Measurements of the distance from the origin of the anterior talofibular ligament $(\mathrm{mm})$.

\begin{tabular}{lllll}
\hline Specimen & SPN $60^{\circ}$ & SPN $90^{\circ}$ & IER & ATFL \\
\hline 1 & 27 & 34 & 15 & 13 \\
2 & 31 & 43 & 28 & 19 \\
3 & 28 & 48 & 18 & 22 \\
4 & 17 & 24 & 20 & 23 \\
5 & 22 & 29 & 19 & 23 \\
6 & 32 & 43 & 21 & 25 \\
7 & 21 & 25 & 20 & 24 \\
8 & 20 & 25 & 14 & 19 \\
9 & 34 & 46 & 29 & 20 \\
10 & 35 & 37 & 23 & 24 \\
11 & 25 & 28 & 20 & 29 \\
12 & 24 & 26 & 16 & 20 \\
13 & 21 & 24 & 14 & 17 \\
14 & 22 & 27 & 17 & 18 \\
15 & 22 & 26 & 22 & 18 \\
& & & & \\
Mean \pm SD & $25 \pm 6$ & $32 \pm 9$ & $20 \pm 5$ & $21 \pm 4$ \\
Range & $17-35$ & $24-48$ & $14-29$ & $13-29$ \\
\hline
\end{tabular}

SPN - superficial peroneal nerve. IER - inferior extensor retinaculum. ATFL anterior talofibular ligament. SD - standard deviation. 


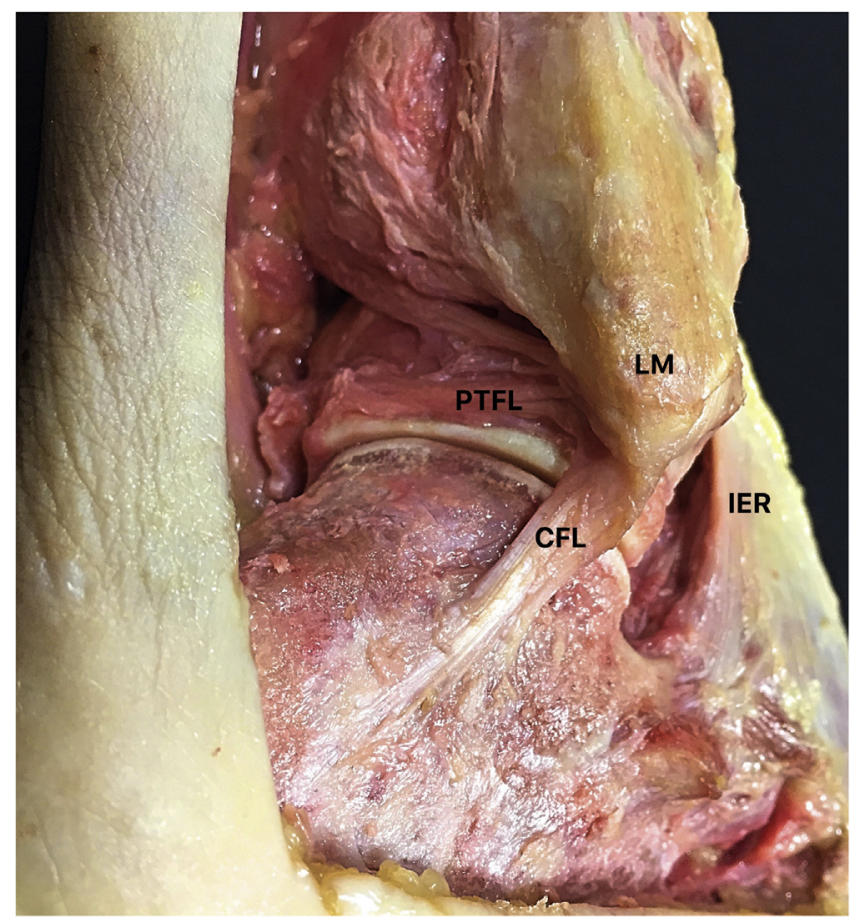

Fig. 6. Posterolateral view of an extensive dissection of the lateral ligaments in a right ankle. LM - lateral malleolus; CFL - calcaneofibular ligament; PTFL posterior talofibular ligament; IER - inferior extensor retinaculum.

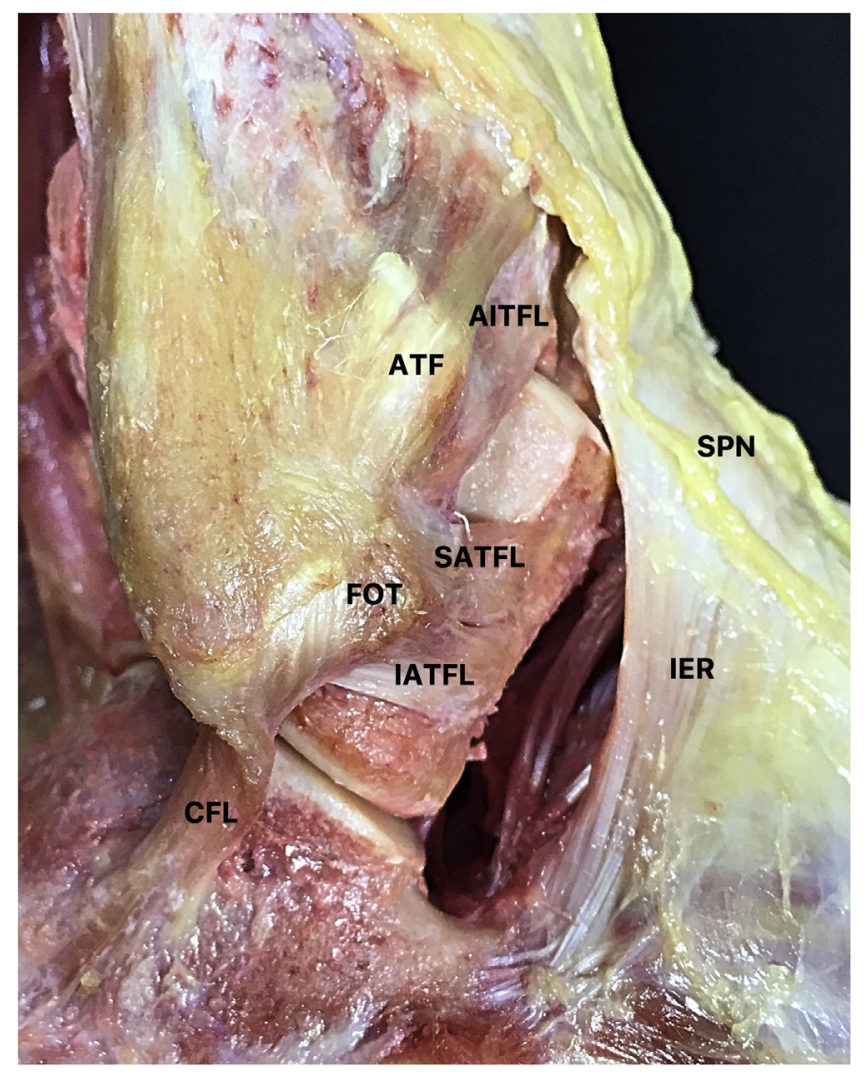

Fig. 7. Lateral view of an extensive dissection of the lateral ligaments in a right ankle. SATFL - superior band of the anterior talofibular ligament; IATFL - inferior band of the anterior talofibular ligament; CFL - calcaneofibular ligament; AITFL antero-inferior tibiofibular ligament; SPN - superficial peroneal nerve; IER inferior extensor retinaculum; FOT - fibular obscure tubercle; ATF - anterior tubercle of the fibula. was $25 \mathrm{~mm}$, but there was a wide range of distances from 17 to $35 \mathrm{~mm}$. The nerve lateral excursion should also be taken in account when placing the anterolateral portal [26]. We hypothesize that a more lateral position of the portal, lateral to the SPN, could be advised in order to avoid damage with the placement of the portal or passing of subcutaneous sutures.

Furthermore, most of the mini-invasive repair techniques describe an accessory incision, anterior to the tip of the lateral malleolus. At $90^{\circ}$ in relation to the axis of the lateral malleolus, the mean distance of the SPN from the ATFL origin center was $32 \mathrm{~mm}$. But this distance had the highest standard deviation $(9 \mathrm{~mm})$ and a range of $24-48 \mathrm{~mm}$. This variability and the difference of $24 \mathrm{~mm}$ in the range creates uncertainty and increases the risk of nerve damage when placing an accessory incision. Probably, a more distal position of this decreases the risk of damage, as the nerve runs further anterior.

In addition, an augmentation of the repair of the ATFL with the IER is frequently made with the passage of one of the sutures subcutaneously in a location anterior to the lateral malleolus.

The average difference between the distance of the SPN and the IER from the ATFL origin at $90^{\circ}$ in relation to the axis of the lateral malleolus was $13 \mathrm{~mm}$, and the minimal distance observed was $4 \mathrm{~mm}$. So the incorporation of the IER in the repair without direct visualization can cause lesion to the SPN, either by entrapment or irritation by prominent suture knots.

The IER anatomical variability and its resistance to proximal mobilization toward the ATFL origin as led to the hypothesis that, in most cases, the structure used to reinforce the ATFL repair is not the IER itself, but the sural fascia [27].

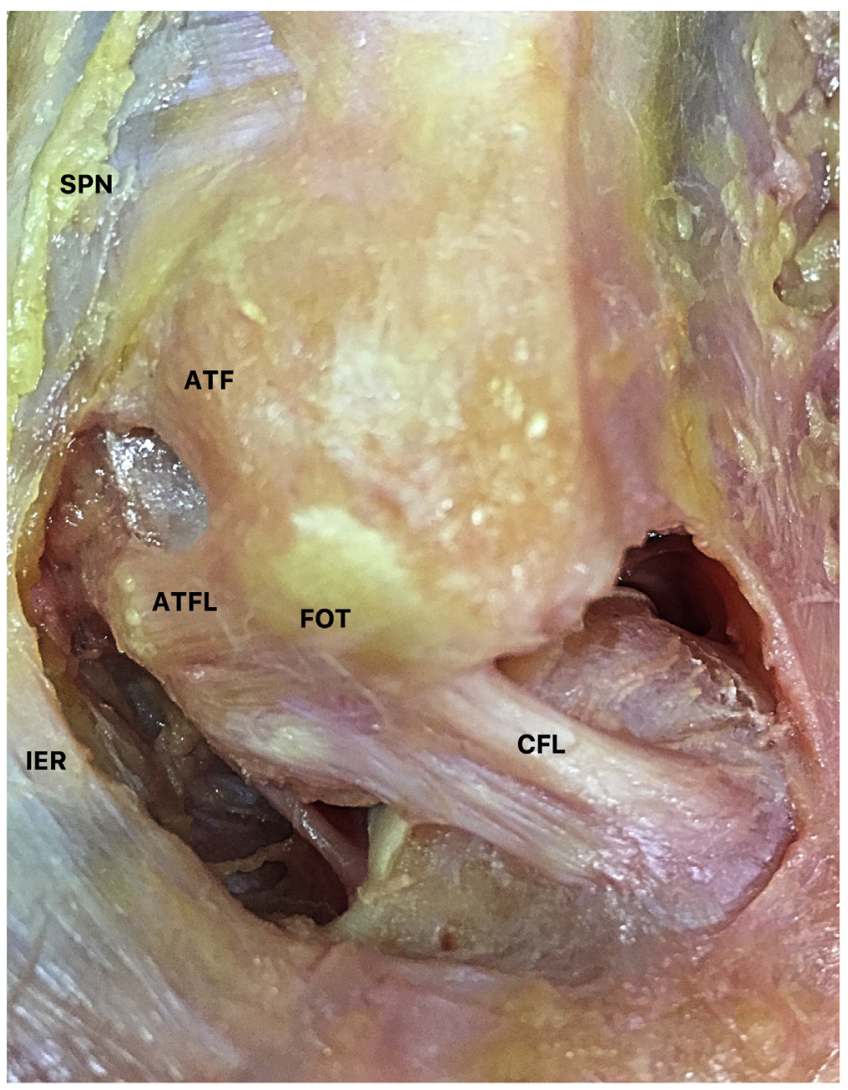

Fig. 8. Lateral view of an extensive dissection of the lateral ligaments in a left ankle. ATFL - anterior talofibular ligament; CFL - calcaneofibular ligament; SPN superficial peroneal nerve; IER - inferior extensor retinaculum; FOT - fibular obscure tubercle; ATF - anterior tubercle of the fibula. 
In our study the delimitation of the borders of the IER was not clear in some cases, as this structure is a continuous of the sural fascia. Nonetheless it was less variable then the SPN, the mean distance \pm SD to the ATFL origin center was $20 \pm 5$ (range 14-29) $\mathrm{mm}$.

Most authors use an accessory incision $10-20 \mathrm{~mm}$ anterior to the tip of the lateral malleolus in order to pass a suture trough the IER. Between these limits, we agree with the preposition that in some cases the augmentation is made with the sural fascia and not the IER. Moreover, its mobilization to lean it to the malleolus seemed difficult, because it was not a very elastic structure in our observation [27].

Since the superior band of the ATFL probably restricts inversion in plantarflexion, the most common position of the foot at the time of injury, it may be the more important of the bands [28], and that is the reason why we choose to measure this band when there were multiple bands. In our work there was no triple-band ATFL observed, and in fact, it seems a less frequent anatomic variant $[20,25]$. Nevertheless, in the review of the articles presented in Table 1, the morphology of the ATFL was not a factor taken into consideration when deciding the type of repair [9-19].

The fibular obscure tubercle was recently reported as landmark to assist mini-invasive procedures to treat chronic ankle instability, as it was near the intersection of the ATFL and CFL [29]. In our study the fibular obscure tubercle was present in most of the specimens, but it's location was more related to the center of the ATFL origin than the intersection of the ATFL and CFL. Nontheless this is an observational opinion, as measures were not made (Figs. 7 and 8). In some specimens (four) there was a small expansion of ligament tissue between the ATFL and the CFL, but the inconsistency of this finding makes a theoretical tensioning of the CFL by repair of the ATFL implausible. We found a mean length of $21 \mathrm{~mm}$ of the ATFL, similar to other results described in the literature [30].

The extrapolation of the results to living tissue is an inherent limitation of the present cadaver study. Moreover, it does not take into account a possible anatomical distortion in an ankle with chronic instability.

In conclusion, the treatment of chronic ankle instability through minimally invasive techniques, namely with suture anchors, has some risk of complications. Most of these seem to be linked to the close anatomic relations between the structures involved, and the variability of the SPN.

In the techniques where an accessory incision is made to include the IER in the repair, the more anterior the placement, the better the chance to incorporate the IER itself than the sural fascia. But this should not surpass the $22 \mathrm{~mm}$ distance from the lateral malleolus due to the risk of damaging the SPN, according to our results.

\section{Conflict of interest}

The authors declare that they have no conflict of interests.

\section{Authors contribution}

All authors were fully involved in the study and preparation of the manuscript. This material has not been and will not be submitted for publication elsewhere.

\section{Funding}

No funding was received for the study itself or for editorial assistance.

\section{References}

[1] Brostrom L. Sprained ankles. V. Treatment and prognosis in recent ligament ruptures. Acta Chir Scand 1966;132:537-50.

[2] Guillo S, Bauer T, Lee JW, Takao M, Kong SW, Stone JW, et al. Consensus in chronic ankle instability: aetiology, assessment, surgical indications and place for arthroscopy. Orthop Traumatol Surg Res 2013;99S:S411-9.

[3] Hiller CE, Kilbreath SL, Refshauge KM. Chronic ankle instability: evolution of the model. J Athl Train 2011;46:133-41.

[4] DiGiovanni BF, Fraga CJ, Cohen BE. Associated injuries found in chronic lateral ankle instability. Foot Ankle Int 2000;21:809-15.

[5] Hintermann B, Boss A, Schafer D. Arthroscopic findings in patients with chronic ankle instability. Am J Sports Med 2002;30:402-29.

[6] Kerr H-L, Bayley E, Jackson R, Kothari P. The role of arthroscopy in the treatment of functional instability of the ankle. Foot Ankle Surg 2013;19 (December (4)):273-5.

[7] Hawkins RB. Arthroscopic stapling repair for chronic lateral instability. Clin Podiatr Med Surg 1987;4:875-83.

[8] Lui TH. Arthroscopic-assisted lateral ligamentous reconstruction in combined ankle and subtalar instability. Arthroscopy 200723(5) 554.e1-5.

[9] Corte-Real NM, Moreira RM. Arthroscopic repair of chronic lateral ankle instability. Foot Ankle Int 2009;30:213-7.

[10] Nery C, Raduan F, Del Buono A, Asaumi ID, Cohen M, Maffulli N. Arthroscopicassisted Broström-Gould for chronic ankle instability: a long-term follow-up. Am J Sports Med 2011;39:2381-8.

[11] Kim ES, Lee KT, Park JS, Lee YK. Arthroscopic anterior talofibular ligament repair for chronic ankle instability with a suture anchor technique. Orthopedics 201134(4).

[12] Vega J, Golano P, Pellegrino A, Rabat E, Pena F. All- inside arthroscopic lateral collateral ligament repair for ankle instability with a knotless suture anchor technique. Foot Ankle Int 2013;34:1701-9.

[13] Cottom JM, Rigby RB. The "all inside" arthroscopic Broström procedure: a prospective study of 40 consecutive patients. J Foot Ankle Surg 2013;52 (5):568-74.

[14] Labib SA, Slone HS. Ankle arthroscopy for lateral ankle instability. Tech Foot Ankle Surg 2015;14:25-7.

[15] Acevedo JI, Mangone P. Arthroscopic brostrom technique. Foot Ankle Int 2015;36(4):465-73.

[16] Matsui K, Takao M, Miyamoto W, Matsushita T. Early recovery after arthroscopic repair compared to open repair of the anterior talofibular ligament for lateral instability of the ankle. Arch Orthop Trauma Surg 2016;136 (1):93-100.

[17] Yoo JS, Yang EA. Clinical results of an arthroscopic modified Brostrom operation with and without an internal brace. J Orthop Traumatol 2016;17 (4):353-60.

[18] Yeo ED, Lee KT, Sung IH, Lee SG, Lee YK. Comparison of all-inside arthroscopic and open techniques for the modified Broström procedure for ankle instability. Foot Ankle Int 2016;37(10):1037-45.

[19] Cottom JM, Baker JS, Richardson PE. The "all-inside" arthroscopic Broström procedure with additional suture anchor augmentation: a prospective study of 45 consecutive patients. J Foot Ankle Surg 2016;55(6):1223-8.

[20] Golano P, Vega J, Leeuw P, Malagelada F, Manzanares M, Gotzens V, et al. Anatomy of the ankle ligaments: a pictorial essay. Knee Surg Sports Traumatol Arthrosc 2010;18:557-69.

[21] Buzzi R, Todescan G, Brenner E, Segoni F, Inderster A, Aglietti P. Reconstruction of the lateral ligaments of the ankle: an anatomic study with evaluation of isometry. J Sports Traumatol Relat Res 1993;15:55-74.

[22] Behrens SB, Drakos M, Lee BJ, Paller D, Hoffman E, Koruprolu S, DiGiovanni CW. Biomechanical analysis of Brostrom versus Brostrom-Gould lateral ankle instability repairs. Foot Ankle Int 2013;34(4):587-92.

[23] Ucerler H, Ikiz AA, Uygur M. A cadaver study on preserving peroneal nerves during ankle arthroscopy. Foot Ankle Int 2007:28(11):1172-8.

[24] Woo SB, Wong TM, Chan WL, Yen CH, Wong WC, Mak KL. Anatomic variations of neurovascular structures of the ankle in relation to arthroscopic portals: a cadaveric study of Chinese subjects. J Orthop Surg (Hong Kong) 2010;18(1):715.

[25] Milner CE, Soames RW. Anatomical variations of the anterior talofibular ligament of the human ankle joint. J Anat 1997;191:457-8.

[26] Leeuw PAJ, Golanó P, Sierevelt IN, van Dijk CN. The course of the superficial peroneal nerve in relation to the ankle position: anatomical study with ankle arthroscopic implications. Knee Surg Sports Traumatol Arthrosc 2010;18:6127.

[27] Dalmau-Pastor M, Yasui Y, Calder JD, Karlsson J, Kerkhoffs GM, Kennedy JG. Anatomy of the inferior extensor retinaculum and its role in lateral ankle ligament reconstruction: a pictorial essay. Knee Surg Sports Traumatol Arthrosc 2016:24(4):957-62.

[28] Van den Bekerom MP, Oostra RJ, Alvarez PG, van Dijk CN. The anatomy in relation to injury of the lateral collateral ligaments of the ankle: a current concepts review. Clin Anat 2008;21(7):619-26.

[29] Matsui K, Oliva XM, Takao M, Knee Surg. Sports Traumatol. Arthrosc. 2016, doi: http://dx.doi.org/10.1007/s00167-016-4218-7.

[30] Taser F, Shafiq Q, Ebraheim NA. Anatomy of lateral ankle ligaments and their relationship to bony landmarks. Surg Radiol Anat 2006;28(4):391-7. 